\title{
Combined detection of the expression of Nm23-H1 and p53 is correlated with survival rates of patients with stage II and III colorectal cancer
}

\author{
YINYING WU $^{1}$, YI LI ${ }^{1}$, XIAOAI ZHAO ${ }^{1}$, DANFENG DONG ${ }^{1}$, \\ CHUNHUI TANG ${ }^{2}$, ENXIAO LI ${ }^{1}$ and QIANQIAN GENG ${ }^{3}$

\begin{abstract}
${ }^{1}$ Department of Medical Oncology, The First Affiliated Hospital of Xi'an Jiaotong University, Xi'an, Shaanxi 710061; The First Affiliated Hospital of Xi'an Jiaotong University, Xi'an, Shaanxi 710061, P.R. China
\end{abstract} \\ ${ }^{2}$ Department of Geriatrics, Shaanxi Provincial People Hospital, Xi'an, Shaanxi 710068; ${ }^{3}$ Department of Nuclear Medicine,
}

Received June 29, 2015; Accepted October 26, 2016

DOI: $10.3892 / \mathrm{ol} .2016 .5425$

\begin{abstract}
Molecular tumor markers hold considerable promise for accurately predicting the recurrence and progression of colorectal cancer (CRC) in patients. However, in the majority of cases, single marker analysis has been found to have low accuracy, and is of little practical use in clinical practice. The present study investigated the prognostic value of the combined detection of the protein expression of metastasis suppressor 23-H1 (Nm23-H1) and p53 using immunohistochemical analysis, and the mRNA expression levels were analyzed using reverse transcription-quantitative polymerase chain reaction in 110 cases of stage II and III CRC. The results revealed that the expression levels of Nm23-H1 in CRC tissues were lower, compared with those in normal tissues $\left(\chi^{2}=18.249 ; \mathrm{P}<0.001\right)$, and the protein expression levels of $\mathrm{p} 53$ were higher in the $\mathrm{CRC}$ tissues $\left(\chi^{2}=23.940 ; \mathrm{P}<0.001\right)$; although the mRNA expression levels of $\mathrm{Nm} 23-\mathrm{H} 1$ and $\mathrm{p} 53$ presented with the same trend. The protein expression of $\mathrm{Nm} 23-\mathrm{H} 1$ was correlated with lymph node metastases $\left(\chi^{2}=11.847 ; \mathrm{P}=0.001\right)$ and pathological patterns $\left(\chi^{2}=6.911 ; \mathrm{P}=0.032\right)$. However, it did not correlate with patient gender or age, or with tumor World Health Organization classification or invasive depth $(\mathrm{P}>0.05)$. No significant correlation was observed between the expression of p53 and clinicopathological features $(\mathrm{P}>0.05)$. Patients with CRC with Nm23-H1(+)/p53(-) tumors had increased survival
\end{abstract}

Correspondence to: Dr Qianqian Geng, Department of Nuclear Medicine, The First Affiliated Hospital of Xi'an Jiaotong University, 277 Yanta West Road, Xi'an, Shaanxi 710061, P.R. China

E-mail: gqq_1129@sina.com

Dr Enxiao Li, Department of Medical Oncology, The First Affiliated Hospital of Xi'an Jiaotong University, 277 Yanta West Road, Xi'an, Shaanxi 710061, P.R. China

E-mail: doclienxiao@sina.com

Key words: colorectal cancer, p53, Nm23-H1, immunohistochemistry, prognosis rates, with a five-year overall survival rate of $83.8 \%$ and a five-year disease-free survival rate of $70.2 \%$. The five-year overall survival rates in other study cohorts were lower, compared with the Nm23-H1(+)/p53(-) group $(\mathrm{P}<0.0125)$, and this was the same for the five-year disease-free survival rate $(\mathrm{P}<0.0125)$. In conclusion, the present study demonstrated that the combined detection of the protein expression of Nm23-H1 and p53 was associated with the long term survival rates of patients with stage II and III CRC; and this may offer potential for use as a predictor of survival rates in patients with CRC.

\section{Introduction}

Colorectal cancer (CRC) is the third most common type of cancer and the leading cause of cancer-associated mortality in men and women in the United States (1). The same trends in incidence and mortality rates are present in China, with its incidence rapidly increasing by $4.2 \%$ each year (2). Metastases is the predominant cause of cancer-associated mortality. The most important CRC prognostic factor in clinics is the American Joint Committee on Cancer tumor-node-metastasis (TNM) staging, which is determined by the depth of invasion, the involvement of pericolorectal lymph nodes and distant metastasis (3). It is generally considered that patients with stage II and III CRC have favorable prognoses. However, data have shown that the rate of recurrence and metastasis for these patients is as high as $30 \%$ (4). In previous years, several molecular factors have been examined as prognostic and predictive factors for $\mathrm{CRC}$, including small mothers against decapentaplegic 4, BRAF and extracellular signal-regulated kinase 1/2 (5,6). However, efficient clinical predictive markers to guide the screening of patients with CRC at high risk of recurrence and metastasis remain to be elucidated. Therefore, it is essential to identify novel prognostic and predictive factors for CRC, other than the TNM stage, in order to minimize adverse effects and maximize therapeutic effects in treating patients with CRC.

The development of CRC is a complex process based on the accumulation of several genetic factors, including alterations in oncogenes, tumor suppressor genes, and genes associated 
with DNA damage and repair (7). The Nm23-H1 gene is a metastasis suppressor gene, the low expression of which can promote tumor occurrence and metastasis during tumor progression (8). As $\mathrm{Nm} 23-\mathrm{H} 1$ was originally identified as a metastasis suppressor protein, its expression has been correlated with tumor metastatic potential in various types of human carcinoma, primarily in ductal breast cancer (9) and CRC (7). Low expression levels of Nm23-H1 have been associated with poor prognosis in gastric adenocarcinoma, breast cancer, hepatocellular carcinoma and ovarian carcinoma (9-12). p53 is a transcription factor involved in regulating cell cycle arrest and apoptosis in response to DNA damage and cellular stress, and is thereby critical in protecting cells from malignant transformation $(13,14)$. It has been shown that analysis of the expression of p53 offers considerable promise for accurately predicting recurrence and progression rates in patients with tumors, including gastric cancer (15) and breast cancer (16). Although the value of the expression of p53 in the prognosis of patients with CRC has been widely investigated $(17,18)$, data analysis on the use of the expression of p53 for long-term survival rate prediction in patients with CRC is limited (17).

The present study aimed to investigate the expression levels of Nm23-H1 and p53 in stage II and III CRC tissues, and examine their association with the clinicopathological features of the patients and tumors. The effect of the combined detection of $\mathrm{Nm} 23-\mathrm{H} 1$ and $\mathrm{p} 53$ on the survival rates of patients with CRC was also evaluated.

\section{Materials and methods}

Patients and specimens. A total of 110 paraffin-embedded samples were collected from patients with CRC who underwent surgery at the First Affiliated Hospital of Xi'an Jiaotong University (Xi'an, China) between 2001 and 2006. Medical records of patients enrolled in the study were retrospectively analyzed. Pathological diagnoses were classified in accordance with the World Health Organization (WHO) criteria (19), and staging was performed according to the American Joint Committee on Cancer TNM classification (20,21). In addition, 53 cases of paraffin-embedded normal colorectal specimens were included from patients who underwent colorectal biopsy by colonoscopy. The present study was approved by the Ethics Committee of the First affiliated Hospital of Xi'an Jiaotong University.

Among the 110 patients with CRC, 58 (52.73\%) were men and $52(47.27 \%)$ were women; $44(40.00 \%)$ patients were $<60$ years old and $66(60.00 \%)$ were $>60$ years old. In terms of staging, $56(50.9 \%)$ patients were in stage II and $54(49.1 \%)$ patients were in stage III. Regarding site, 65 (59.09\%) tumors were located in the colon and $45(40.91 \%)$ tumors were located in the rectum, of which $37(33.63 \%)$ tumors had a diameter $<5 \mathrm{~cm}$ (including $5 \mathrm{~cm}$ ) and $73(66.36 \%)$ tumors $>5 \mathrm{~cm}$. According to histological grade, 93 (84.55\%) tumors were well to moderately differentiated, whereas 17 (15.45\%) tumors were poorly differentiated. According to the WHO classification of CRC, 92 (83.64\%) tumors were classified as adenocarcinomas, $12(10.91 \%)$ tumors were classified as mucinous carcinomas, five $(4.55 \%)$ tumors were classified as undifferentiated carcinomas, and one case was designated as unclear. According to the TNM classification, 48 (43.64\%) tumors exhibited T1-3 infiltration, and $62(56.36 \%)$ tumors exhibited T4 infiltration. In addition, 56 (50.91\%) cases were without lymphatic metastasis, whereas 54 (49.09\%) cases exhibited lymphatic metastasis, including 41 cases with $<12$ lymph nodes in biopsy $(41 / 54)$ and 13 cases with $>12(13 / 54)$ lymph nodes in biopsy. In the control group, there were 19 women and 34 men, aged between 32 and 79 years with a median age of 59 years.

Immunohistochemical analysis. Immunohistochemical staining for $\mathrm{p} 53$ and $\mathrm{Nm} 23-\mathrm{H} 1$ was performed using a standard avidin-biotin complex method. All specimens were fixed in $10 \%$ neutral-buffered formalin overnight at room temperature, embedded in paraffin and cut into $4-\mu$ m-thick sections. Subsequently, the sections were deparaffinized in xylene baths and rehydrated with a series of ethanol solutions for $5 \mathrm{~min}$ each. A microwave was used for antigen retrieval for $30 \mathrm{~min}$ in $0.01 \mathrm{M}$ of sodium citrate. Following blocking of endogenous peroxidase activity with $5 \%$ hydrogen peroxidase for $10 \mathrm{~min}$, incubation with the primary antibody was performed for $2 \mathrm{~h}$ at room temperature. Mouse monoclonal antibody against p53 (sc-47698; Santa Cruz Biotechnology, Inc., Santa Cruz, CA, USA) was used at 1:500 dilution, and a mouse monoclonal antibody against Nm23-H1 (sc-514515; Santa Cruz Biotechnology, Inc.) was used at 1:100 dilution. The sections were then incubated with horseradish peroxidase-conjugated secondary antibody (SP-9002; Zhongshan Golden Bridge Biotechnology, Peking, China) at room temperature for $30 \mathrm{~min}$. The tissue sections were then washed in tris-buffered saline for $10 \mathrm{~min}$, with 3-amino-9-ethylcarbazole used as a chromogen, and hematoxylin counterstaining was performed.

Under a light microscope (Olympus BX53; Olympus Corporation, Tokyo, Japan), p53 protein staining was observed to be localized in the nucleus, and $\mathrm{Nm} 23-\mathrm{H} 1$ protein was primarily expressed in the cytoplasm. Positive staining was visible as brown-yellow nuclear/cytoplasmic staining for the respective antibody. Antigen expression was evaluated in a semi-quantitative manner. Immunoreactivity was scored based on the immunoreactive cell percentage and staining intensity of each slide in each low power field of three randomly selected microscopic fields per slide (magnification, x100). The immunoreactive cell percentage was defined as follows: Staining index 0 , tissue with no staining; staining index 1 , tissue with faint or moderate staining in $<25 \%$ of tumor cells; staining index 2 , tissue with moderate or marked staining in $25-75 \%$ of tumor cells; staining index 3 , tissue with marked staining in $>75 \%$ of tumor cells. In addition, the staining intensity, compared with the background, was defined as follows: 0 , colorless; 1 , cream-colored; 2, brown-yellow; 3 , tan. The mean product of these two indices from three fields was defined as the final score: 0-2 (-), 3-4 (+), 5-7 (++), 8-9 (+++).

Reverse transcription-quantitative polymerase chain reaction $(R T-q P C R)$ analysis. Tissues were cut and incubated with diethylpyrocarbonate. After full grinding, the tissue suspension obtained through the strainer was collected and used for RNA extraction. Total RNA was extracted from the frozen tumor and normal colorectal tissue suspensions using an RNA fast 200 kit (Fastagen Biotechnology, Co., Ltd., Shanghai, China). The RT reaction was performed using a PrimeScript RT Reagent kit (Takara Bio, Inc., Otsu, Japan). Subsequently, 
A

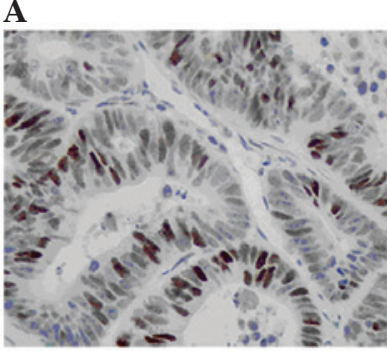

$\mathbf{E}$

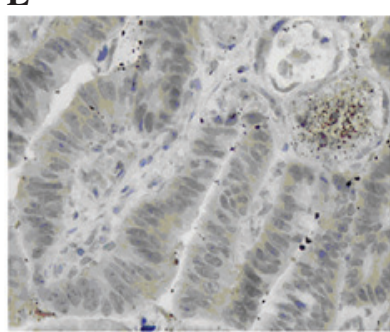

B

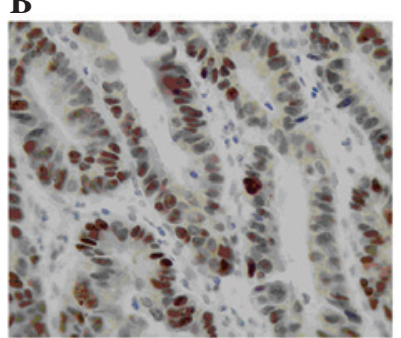

F

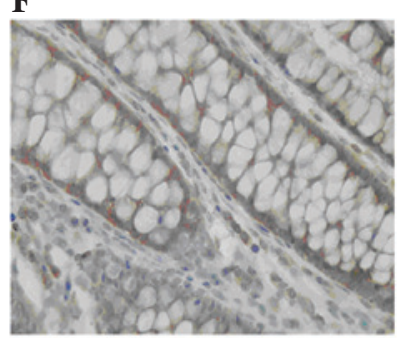

C

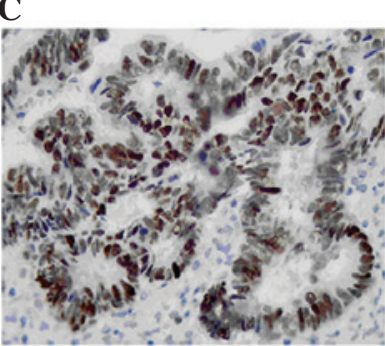

G

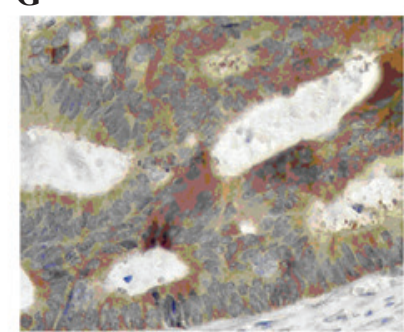

D

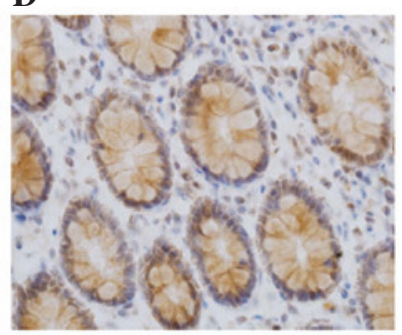

H

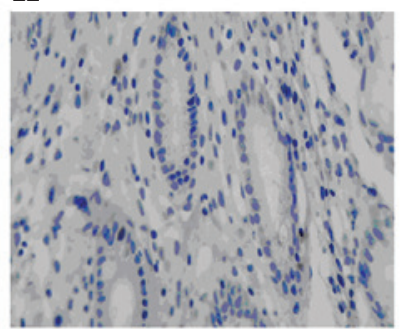

Figure 1. Immunohistochemical analysis of Nm23-H1 and p53. (A) Weak, (B) moderate and (C) marked positive Nm23-H1 staining in CRC; (D) positive Nm23-H1 staining in normal colorectal tissues; $(\mathrm{E})$ weak, $(\mathrm{F})$ moderate and $(\mathrm{G})$ marked positive p53 staining in CRC; (H) negative p53 staining in normal CRC (magnification, $\mathrm{x} 400$ ). CRC, colorectal cancer.

SYBR Premix EX $\mathrm{Taq}^{\mathrm{TM}}$ II (Takara Bio, Inc,) was used to perform qPCR analysis, according to the manufacturer's protocols, and the results were detected using a Prism 7500 real-time PCR detection system (Applied Biosystems; Thermo Fisher Scientific, Waltham, MA, USA). ). The reaction conditions were as follows: $94^{\circ} \mathrm{C}$ for $3 \mathrm{~min}$, followed by 25 cycles of $94^{\circ} \mathrm{C}$ for $30 \mathrm{sec}, 59.6^{\circ} \mathrm{C}$ for $30 \mathrm{sec}$ and $72^{\circ} \mathrm{C}$ for $30 \mathrm{sec}$. Oligonucleotide primers for p53, Nm23-H1 and GAPDH were synthesized by Sangon (Sangon Biotech Co., Ltd., Shanghai, China). The primer sequences were as follows: 553 forward, 5'-CCTCAGCATCTTATCCGAGTGG-3' and reverse, 5'-TGG ATGGTGGTACAGTCAGAGC-3'; Nm23-H1 forward, 5'-TTG ACCGGGGTAGAGAACTC-3' and reverse, 5'-TCTCAGTAC TTCCCGTGACC-3-'; and GAPDH forward, 5'-AGGTCC ACCACTGACACGTT-3' and reverse, 5'-GCCTCAAGATCA GCAAT-3'. GAPDH was used as an internal reference gene. The relative mRNA expression levels were calculated using the delta-delta quantification cycle method, as follows: Delta $\mathrm{Ct}=\mathrm{Ct}_{\text {Target }}-\mathrm{Ct}_{\mathrm{GAPDH}} \cdot$ (22).

Follow-up. The patients with CRC enrolled in the present study were followed up at the outpatient clinic, or by telephone call or letter. Follow-up was performed once every 3 months in the first year following surgery, and once every 6 months subsequently. As of December 2011, the follow-up duration for the 110 cases ranged between 4 and 102 months, with a median duration of 72 months.

Statistical analysis. Statistical analysis was performed using SPSS software version 17.0 (SPSS, Inc. Chicago, USA). Data are presented as the mean \pm standard deviation. Enumeration data were analyzed using the $\chi^{2}$-test. Student's $t$-test was used for comparison between two groups. Bonferroni correction was used in multiple comparisons. Survival analysis was performed using Kaplan-Meier curves and associated log-rank tests. Correlation analysis was assessed by Spearman's test for ranked data. $\mathrm{P}<0.05$ was considered to indicate a statistically significant difference

\section{Results}

Protein expression of Nm23-H1 and p53 in CRC and normal colon tissues. Positive Nm23-H1 immunostaining was detected in $57.3 \%$ (63/110) of the CRC cases (Fig. 1A-C), and in $90.6 \%$ (48/53) of the normal tissue samples (Fig. 1D). The expression levels of Nm23-H1 in the CRC tissues were significantly lower, compared with those in the normal tissues $\left(\chi^{2}=18.249 ; \mathrm{P}<0.001\right)$. In addition, a significant correlation was observed between lymph node metastasis and the expression of Nm23-H1 $\left(\chi^{2}=11.847, \mathrm{P}=0.001\right)$. CRCs with lymph node metastasis stained positively for Nm23-H1 in 40.7\% (22/54) of the cases, whereas the CRC samples without lymph node metastasis stained positively for Nm23-H1 in $73.2 \%$ (41/56) of the cases. A significant difference was also observed in Nm23-H1 staining according to the WHO classification of the tumors. It was found that $63.0 \%$ (58/92) of the adenocarcinoma tissues, $33.3 \%$ (4/12) of the mucinous carcinoma tissues and $20.0 \%(1 / 5)$ of the undifferentiated carcinoma tissues stained positively for $\mathrm{Nm} 23-\mathrm{H} 1 \quad\left(\chi^{2}=6.911 ; \mathrm{P}=0.032\right)$. However, no correlations were found between the protein expression of Nm23-H1 and the other clinicopathologic features of the patients and tumors, including gender $(\mathrm{P}=0.492)$, age $(\mathrm{P}=0.208)$, tumor location $(\mathrm{P}=0.487)$, tumor size $(\mathrm{P}=0.741)$, grade $(\mathrm{P}=0.500)$ and invasive depth $(\mathrm{P}=0.081)$. The results of these analyses are presented in Table I.

The protein expression levels of p53 in CRC tissues varied. Positive staining was observed as brown granules, predominantly localized in the nucleus. Positive p53 staining was observed in $80 \mathrm{CRC}$ cases (72.7\%; Fig. 1E-G), whereas 30 of the normal tumors were found to be negative for the protein expression of p53 (Fig. 1H). Compared with this observation for CRC tumors, only three cases were positive 
Table I. Association between expression levels of Nm23-H1 and p53 and clinical pathological features of patients with colorectal cancer.

\begin{tabular}{|c|c|c|c|c|c|}
\hline Variable & $\mathrm{n}$ & $\begin{array}{c}\text { Nm23-H1-positive } \\
\text { rate (\%) }\end{array}$ & $\chi^{2}$ (P-value) & $\begin{array}{l}\text { p53-positive } \\
\text { rate }(\%)\end{array}$ & $\chi^{2}$ (P-value) \\
\hline Gender & & & $0.473(0.492)$ & & $0.006(0.938)$ \\
\hline Male & 58 & 60.3 & & 72.4 & \\
\hline Female & 52 & 53.8 & & 73.1 & \\
\hline Age (years) & & & $1.585(0.208)$ & & $1.719(0.190)$ \\
\hline$\leq 60$ & 44 & 50.0 & & 79.5 & \\
\hline$>60$ & 66 & 62.1 & & 68.2 & \\
\hline Tumor location & & & $0.483(0.487)$ & & $0.014(0.905)$ \\
\hline Colon & 65 & 60.0 & & 72.3 & \\
\hline Rectum & 45 & 53.3 & & 73.3 & \\
\hline Tumor size $(\mathrm{cm})$ & & & $0.109(0.741)$ & & $0.244(0.621)$ \\
\hline$\leq 5$ & 37 & 54.1 & & 71.2 & \\
\hline$>5$ & 73 & 58.9 & & 75.7 & \\
\hline Grade $^{a}$ & & & $0.454(0.500)$ & & $0.652(0.102)$ \\
\hline $\mathrm{I}-\mathrm{II}$ & 93 & 55.9 & & 74.2 & \\
\hline III & 17 & 64.7 & & 64.7 & \\
\hline Pathological pattern ${ }^{\mathrm{b}}$ & & & $6.911(0.032)^{\mathrm{c}}$ & & $6.203(0.102)$ \\
\hline Adenocarcinoma & 92 & 63.0 & & 78.1 & \\
\hline Mucinous carcinoma & 12 & 33.3 & & 54.2 & \\
\hline Undifferentiated carcinoma & 5 & 20.0 & & 81.8 & \\
\hline Invasive depth & & & $3.046(0.081)$ & & $0.002(0.969)$ \\
\hline $\mathrm{T} 1-3$ & 48 & 47.9 & & 72.9 & \\
\hline $\mathrm{T} 4$ & 62 & 64.5 & & 72.6 & \\
\hline Lymphatic metastasis & & & $11.847(0.001)^{\mathrm{c}}$ & & $0.547(0.459)$ \\
\hline No & 56 & 73.2 & & 69.6 & \\
\hline Yes & 54 & 40.7 & & 75.9 & \\
\hline
\end{tabular}

${ }^{\mathrm{a}}$ According to the World Health Organization classification of colorectal cancer; ${ }^{\mathrm{b}}$ One case was unclear and was not included. ${ }^{\mathrm{c}} \mathrm{P}<0.05$.

for the expression of p53 in the 53 normal controls $(5.7 \%)$. These results showed that the expression levels of p53 in CRC tissues were significantly higher, compared with those in normal tissues $\left(\chi^{2}=23.940 ; \mathrm{P}<0.001\right)$. No significant correlation was found between the expression of p53 and the analyzed clinicopathological features of the patients and their tumors, including gender $(\mathrm{P}=0.938)$, age $(\mathrm{P}=0.190)$, tumor location $(\mathrm{P}=0.905)$, tumor size $(\mathrm{P}=0.621)$, grade $(\mathrm{P}=0.102)$, pathological pattern $(\mathrm{P}=0.102)$, invasive depth $(\mathrm{P}=0.969)$ and lymphatic metastasis $(\mathrm{P}=0.459)$. The results of these analyses are presented in Table I.

Correlation between the protein expression of $\mathrm{Nm} 23-\mathrm{HI}$ and p53 in CRC tissues. The Nm23-H1-positive CRC cases were divided based on staining intensity: 19 cases were 1+, 27 cases were $2+$ and 17 cases were $3+$. The 80 p53-positive cases were also divided based on staining intensity: 27 cases were $1+, 30$ cases were $2+$, and 23 cases were $3+$ (Table II). The correlation between the protein expression of Nm23-H1 and p53 was analyzed using Spearman's test, and the results revealed that the protein expression of $\mathrm{p} 53$ was negatively correlated with the protein expression of Nm23-H1 ( $\left.r_{\mathrm{s}}=-0.400 ; \mathrm{P}<0.001\right)$.

mRNA expression of Nm23-H1 and p53 in CRC and normal colon tissues. As shown in Fig. 2, the Nm23-H1 gene expression levels at the transcriptional level were found to be significantly increased in the normal colorectal tissues, compared with the CRC tissues $(\mathrm{P}<0.05)$. By contrast, the mRNA expression levels of p53 were significantly decreased in the normal colorectal tissues, compared with the CRC tissues $(\mathrm{P}<0.05)$.

Association between the protein expression levels of Nm23-H1 and 53 and prognosis. The overall survival (OS) rates of the 110 patients with CRC were 4-102 months, with a median OS (mOS) rate of 55 months. The disease-free survival (DFS) rates of patients was 4-89 months, with a median DFS (mDFS) rate of 48 months. The OS and DFS curves are presented in Fig. 3A and B. In addition, further stratified analyses of prognosis with different protein expression levels of Nm23-H1 and p53 was performed. There was a statistical difference in the five-year survival rate of patients with various $\mathrm{Nm} 23-\mathrm{H} 1$ 
Table II. Correlation of protein expression of $\mathrm{Nm} 23-\mathrm{H} 1$ and p53 in 110 colorecatal cancer tissue samples.

\begin{tabular}{lcrrrr}
\hline & \multicolumn{4}{c}{ Nm23-H1 expression } & \\
\cline { 2 - 4 } p53 expression & Negative & $1+$ & $2+$ & $3+$ & Total \\
\hline Negative & 5 & 6 & 13 & 7 & 31 \\
$1+$ & 15 & 1 & 11 & 3 & 30 \\
$2+$ & 16 & 10 & 3 & 6 & 35 \\
$3+$ & 11 & 2 & 0 & 1 & 14 \\
Total & 47 & 19 & 27 & 17 & 110 \\
\hline
\end{tabular}

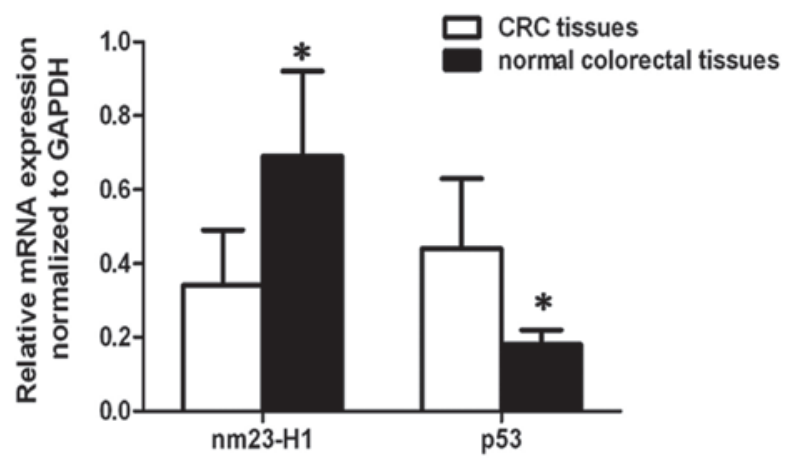

Figure 2. mRNA expression levels of Nm23-H1 and p53 in CRC and normal colorectal tissues. mRNA expression levels of Nm23-H1 were significantly lower in CRC tissues, compared with normal tissues. mRNA expression levels of p53 were significantly higher in CRC tissues, compared with normal colorectal tissues. ${ }^{*} \mathrm{P}<0.05$, vs CRC tissues. CRC, colorectal cancer.

and $\mathrm{p} 53$ expression statuses $\left(\chi^{2}=33.429, \mathrm{P}<0.001\right)$. Patients with $\mathrm{Nm} 23-\mathrm{H} 1(+) / \mathrm{p} 53(-)$ tumors had improved prognosis, and the five-year survival rate $(83.8 \%)$ was significantly higher, compared with that in patients with $\mathrm{Nm} 23-\mathrm{H} 1(-) / \mathrm{p} 53(+)$ tumors $(20.00 \% ; \mathrm{P}=0.008), \mathrm{Nm} 23-\mathrm{H} 1(+) / \mathrm{p} 53(+)$ tumors $(23.8 \% ; \mathrm{P}<0.001)$ and $\mathrm{Nm} 23-\mathrm{H} 1(-) / \mathrm{p} 53(-)$ tumors $(30.8 \%$; $\mathrm{P}<0.001)$, respectively. In addition, no significant differences in prognosis were found among the latter three subgroups $(\mathrm{P}>0.0125)$. The five-year DFS rate revealed a similar trend as the five-year OS rate $\left(\chi^{2}=18.108, \mathrm{P}<0.001\right)$. The five-year DFS rates of patients with $\mathrm{Nm} 23-\mathrm{H} 1(+) / \mathrm{p} 53(-)$ tumors (70.2\%) were significantly higher, compared with those in patients with $\mathrm{Nm} 23-\mathrm{H} 1(+) / \mathrm{p} 53(+)$ tumors $(16.7 \% ; \mathrm{P}<0.001)$ and patients with Nm23-H1(-)/p53(-) tumors (30.8\%; $\mathrm{P}=0.002)$, however, no significant difference in five-year DFS rates were found between patients with $\mathrm{Nm} 23-\mathrm{H} 1(+) / \mathrm{p} 53(-)$ tumors and patients with $\mathrm{Nm} 23(-) / \mathrm{p} 53(+)$ tumors $(20.00 \% ; \mathrm{P}=0.047$; Table III). Taken together, these data showed that patients with Nm23-H1(+)/p53(-) CRC tumors had improved long-term survival rates (Fig. 3C-D).

\section{Discussion}

Molecular tumor markers hold considerable promise for accurately predicting the recurrence and progression of cancer in patients. At present, several markers have been reported to predict the prognosis of patients with CRC, including p53, ki67 and matrix metalloproteinase-2 (18). The Nm23 gene is located at the long arm of chromosome 17 and consists of three subtypes, namely $\mathrm{H} 1, \mathrm{H} 2$ and H3 (23). Nm23-H1 is a tumor metastasis suppressor gene, and numerous studies have shown that it is crucial in regulating cell proliferation and differentiation $(24,25)$. Of note, $\mathrm{Nm} 23-\mathrm{H} 1$ has been shown to be negatively correlated with tumor metastases and prognosis in oophoroma (26) and lung cancer (27). However, its involvement in CRC remains to be fully elucidated $(28,29)$. In the present study, Nm23-H1 protein was positively expressed in 63 of $110 \mathrm{CRC}$ tumor cases, whereas almost all normal colorectal tissues were found to be Nm23-H1-positive (48/53). The gene expression levels of Nm23-H1 were found to be significantly increased in normal colorectal tissues, compared with CRC tissues. The protein expression of Nm23-H1 further decreased in samples with lymph node metastases. It has been revealed (30) that Nm23-H1 can inhibit metastasis in lung cancer by inhibiting epithelial-mesenchymal transition, however, the mechanism of action of Nm23-H1 in CRC remains to be elucidated. It is may be that the high expression level of Nm23-H1 is involved in decreasing CRC cell infiltration and metastasis by reducing tumor cell motility. In the present study, significant differences in the expression and pathological patterns of Nm23-H1 were found. The data showed that the rates of positive protein expression of $\mathrm{Nm} 23-\mathrm{H} 1$ in the undifferentiated carcinoma and mucinous carcinoma were lower, compared with that of adenocarcinoma, which may be one of the reasons for poor prognosis.

The p53 gene is a tumor suppressor gene located in the short arm of chromosome 17, and is key in controlling tumor evolution and progression (31). In normal cells, p53 can induce cell cycle arrest at the G0/G1 phase and cell apoptosis; and when it is mutated, as in the case of several types of tumor, p53 loses its regulatory role and promotes tumor progression (32). Deregulation of cell-cycle machinery involving alterations in p53 is common in bladder cancer (33), breast cancer (34), lung cancer (35) and CRC (36). Significant differences in p53 staining between CRC tissues and normal control tissues have been reported in previous studies $(17,18)$. The results of studies have varied; certain studies have revealed that the protein expression of p53 is lower in CRC tissues, compared with normal colorectal tissues (37), whereas other studies have shown its expression was higher in CRC $(38,39)$. Significant differences in the protein and mRNA expression levels of p53 between CRC and normal colorectal tissues were also found in the present study. The protein and mRNA expression levels of p53 were markedly higher in the CRC tissues, compared with the normal controls tissues The cohort of patients the present study comprised patients with stage II and III CRC. This may be one of the reasons causing high protein expression levels of p53. In addition, other studies have demonstrated that tumor differentiation is correlated with the expression of p53 $(35,36,38)$; wherein, the lower the degree of tumor differentiation, the higher the protein expression of p53. p53 has been confirmed as an important prognostic marker for patients with CRC (28). However, in the present study, no significant correlation was found between the protein expression of $\mathrm{p} 53$ and the clinical pathological features of the patients with CRC or their tumors. 
Table III. Association between the protein expression levels of Nm23-H1 and p53 and prognosis.

\begin{tabular}{|c|c|c|c|c|c|c|c|}
\hline \multirow[b]{2}{*}{ Tumor } & \multicolumn{2}{|c|}{ Number of cases } & \multirow[b]{2}{*}{$5 \mathrm{y}-\mathrm{OS}(\%)$} & \multicolumn{2}{|c|}{ Number of cases } & \multirow[b]{2}{*}{$5 \mathrm{y}$-DFS (\%) } & \multirow[b]{2}{*}{ Total } \\
\hline & $<5$ years & $\geq 5$ years & & $<5$ years & $\geq 5$ years & & \\
\hline Nm23-H1(-)/p53(+) & 4 & 1 & 20.0 & 4 & 1 & 20.0 & 5 \\
\hline Nm23-H1(+)/p53(+) & 32 & 10 & 23.8 & 35 & 7 & 16.7 & 42 \\
\hline Nm23-H1(-)/p53(-) & 18 & 8 & 30.8 & 18 & 8 & 30.8 & 26 \\
\hline Nm23-H1(+)/p53(-) & 6 & 31 & 83.8 & 11 & 26 & 70.2 & 37 \\
\hline Total & 60 & 50 & & 68 & 42 & & 110 \\
\hline
\end{tabular}

5 y-OS, five-year overall survival; 5 y-DFS, five-year disease-free survival.
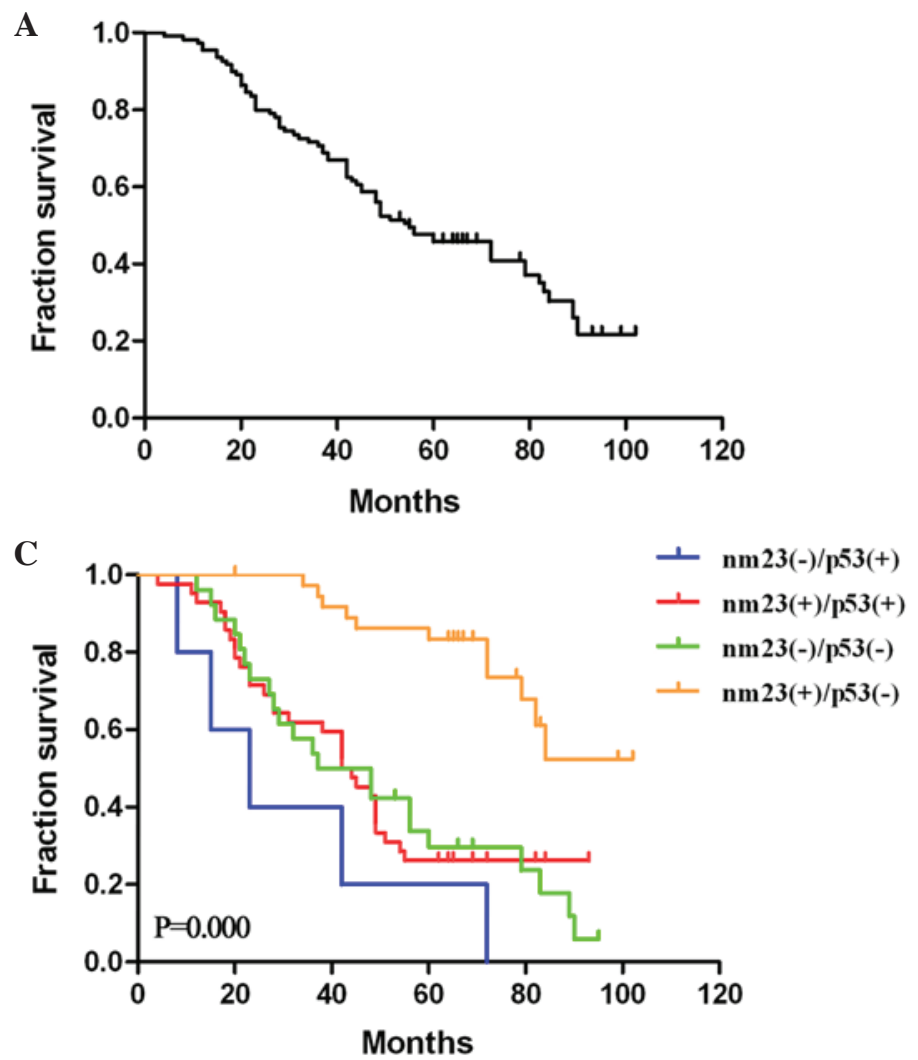
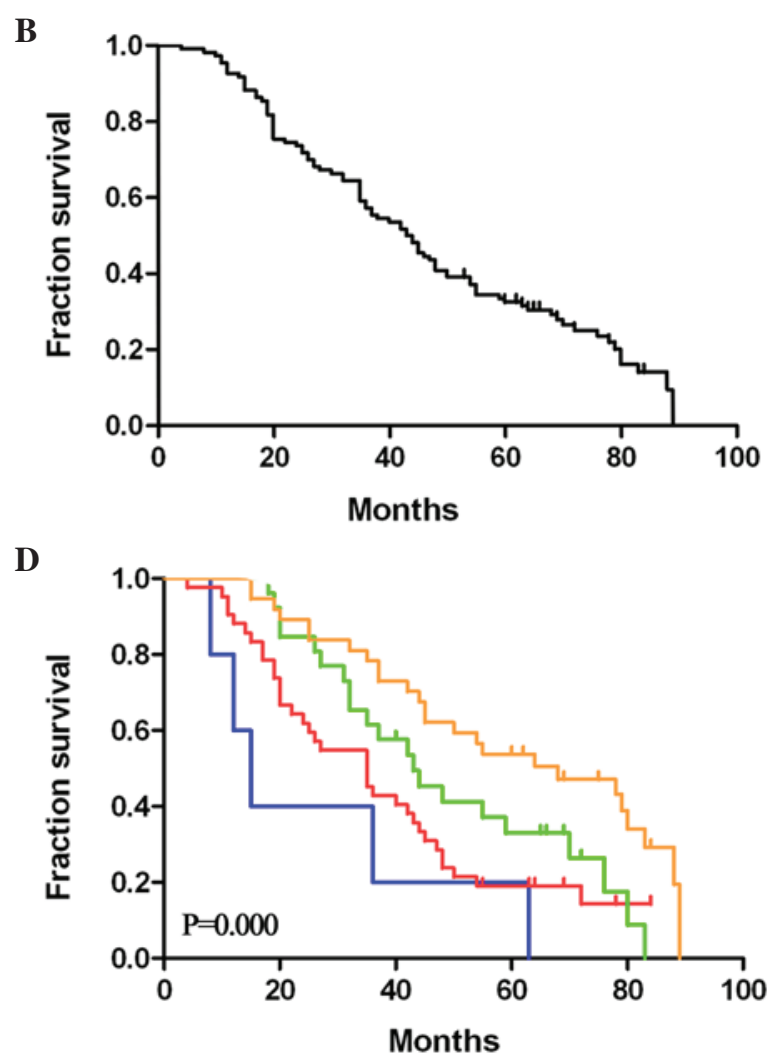

Figure 3. Kaplan-Meier survival curves of patients with stage II and III CRC. (A) Overall survival curve of patients with stage II and III CRC. (B) Disease-free survival curve of patients with stage II and III CRC. (C) Overall survival curve of patients with respect to the co-expression of p53 and Nm23-H1. (D) Disease-free survival curve of patients with respect to the co-expression of p53 and nm23-H1. CRC, colorectal cancer.

As colorectal tumorigenesis is a complex process, it is evident that the usefulness of a single marker for the prediction of prognosis is limited. Therefore, identifying novel molecular markers or the combined detection of two or more tumor markers is warranted.

In the present study, significant differences were found in the five-year OS rates and five-year DFS rates of patients with CRC with different $\mathrm{Nm} 23-\mathrm{H} 1$ and p53 expression status. Patients with Nm23-H1(+)/p53 (-) tumors had a good prognosis, and their five-year OS and five-year DFS rates were markedly higher, compared with those observed in patients with other $\mathrm{Nm} 23-\mathrm{H} 1 / \mathrm{p} 53$ combined protein expression statuses. The functional association between $\mathrm{Nm} 23-\mathrm{H} 1$ and $\mathrm{p} 53$ proteins remains to be elucidated. The regulation of Nm23-H1 by p53 differs in different types of cancer. For example, a negative correlation has been reported in gastric cancer (40). Other studies have indicated marked heterogeneity in the expression of p53 and Nm23-H1 in squamous cell lung cancer (41). In CRC, the expression of $\mathrm{Nm} 23-\mathrm{H} 1$ enhances the inhibition of tumor metastasis and tumor cell invasion, whereas negative expression of the $\mathrm{p} 53$ protein is associated with the inhibition of cancer cell proliferation (42). It is possible that these two proteins act synergistically and affect each other, leading to decreases in tumor cell growth and the invasive ability of cancer cells; thus, prolonging patient survival rates. Therefore, the combined detection of the Nm23-H1 and p53 proteins may provide clinically useful information on the biological behavior and prognosis of CRC. Based on the results of the present study, it can be concluded that the combined 
detection of Nm23-H1 and p53 offers potential for predicting the prognosis of patients with CRC with stage II and III tumors. However, future investigations clarifying the functional association of these two mediators in the progression of CRC and other tumors are warranted.

It can be concluded that two different protein markers be considered when evaluating the clinical outcome of patients with CRC. The combined detection of the protein expression of Nm23-H1 and p53 may provide an index for accurately predicting the prognosis of CRC by providing information on malignancy and biological behaviors.

\section{Acknowledgements}

This study was supported by funds from the National Natural Science Foundation of China (grant no. 81172169), the Key Technologies R \& D Programs of Shaanxi province (grant nos. 2015SF041, 2015SF037 and S2013SF3846), the Fundamental Research Funds for the Central University (grant no. 2015gjhz18) and the Research Fund for the Doctoral Program of Higher Education of China (grant no. 20130201120079).

\section{References}

1. Siegel R, DeSantis C, Virgo K, Stein K, Mariotto A, Smith T, Cooper D, Gansler T, Lerro C, Fedewa S, et al: Cancer treatment and survivorship statistics, 2012. CA Cancer J Clin 62: 220-241, 2012.

2. Nie SF, Yao X, Zhu GB, Zhang JR, Xu YH and Wang X: 1:2 Matched case-control study on risk factors of colorectal cancer in Wuhan. China Public Health 18: 1482-1784, 2002.

3. Li J, Guo BC, Sun LR, Wang JW, Fu XH, Zhang SZ, Poston G and Ding KF: TNM staging of colorectal cancer should be reconsidered by $\mathrm{T}$ stage weighting. Worl J Gastroenterol 20: 5104-5112, 2014

4. Uen YH, Lin SR, Wu DC, Su YC, Wu JY, Cheng TL, Chi CW and Wang JY: Prognostic significance of multiple molecular markers for patients with stage II colorectal cancer undergoing curative resection. Ann Surg 246: 1040-1046, 2007.

5. Voorneveld PW, Jacobs RJ, Kodach LL and Hardwick JC: A meta-analysis of SMAD4 immunohistochemistry as a prognostic marker in colorectal cancer. Transl Oncol 8: 18-24, 2015.

6. Kim HO, Kim BG, Cha SJ, Park YG and Lee TJ: Clinicopathologic significance of BRAF mutation and extracellular signal regulated kinase $1 / 2$ expression in patients with a colorectal adenocarcinoma. Ann Coloproctol 31: 9-15, 2015.

7. Wu HW, Gao LD and Wei GH: hMSH2 and $\mathrm{nm} 23$ expression in sporadic colorectal cancer and its clinical significance. Asian Pac J Cancer Prev 14: 1995-1998, 2013.

8. Suzuki E, Ota T, Tsukuda K, Okita A, Matsuoka K, Murakami M, Doihara $\mathrm{H}$ and Shimizu N: Nm23-H1 reduces in vitro cell migration and the liver metastatic potential of colon cancer cells by regulating myosin light chain phosphorylation. Int J Cancer 108: 207-211, 2004.

9. Bal A, Joshi K, Logasundaram R, Radotra BD and Singh R: Expression of nm23 in the spectrum of pre-invasive, invasive and metastatic breast lesions. Diagn Pathol 3: 23, 2008.

10. Nakayama T, Ohtsuru A, Nakao K, Shima M, Nakata K, Watanabe K, Ishii N, Kimura N and Nagataki S: Expression in human hepatocellular carcinoma of nucleoside diphosphate kinase, a homologue of the $\mathrm{nm} 23$ gene product. J Natl Cancer Inst 84: 1349-1354, 1992.

11. Zhao Z, Lu P, Zhang H, Xu H, Gao N, Li M and Liu C: Nestin positively regulates the Wnt/ß-catenin pathway and the proliferation, survival and invasiveness of breast cancer stem cells Breast Cancer Res 16: 408, 2014.

12. Mandai M, Konishi I, Koshiyama M, Mori T, Arao S, Tashiro H, Okamura H, Normura H, Hiai $\mathrm{H}$ and Fukumoto M: Expression of metastasis-related $\mathrm{nm} 23-\mathrm{H} 1$ and $\mathrm{nm} 23-\mathrm{H} 2$ genes in ovarian carcinomas: Correlation with clinicopathology, EGFR, c-erbB-2, and c-erbB-3 genes, and sex steroid receptor expression. Cancer Res 54: 1825-1830, 1994.
13. Cheok CF, Verma CS, Baselqa J and Lane DP: Translating p53 into clinic. Nat Rev Clin Oncol 8: 25-37, 2011.

14. Vogelstein B, Lane DP and Levine AJ: Suring the p53 network. Nature 408: 307-310, 2000.

15. Liu W, Yu YH, Ouyang XN, Wang L, Wu YM, Chen J and Xiong XS: Clinical significance of p53 and Ki67 expression in gastric cancer. World J. Gastroenterol 19: 367-373, 2011.

16. Ma LL, Zhe W, Wang YQ, Cong XL and Zhang XM: Expression and clinical significance of Survivin and p53 in breast cancer. Chin J Exp Surg 31: 2839-2840, 2014.

17. Zhang YX and Wang Y: Clinical significance and expression of p53 in colorectal cancer. World J Integrated Traditional and Western Med 2: 294-296, 2007.

18. Xiao ZW, He N, Cao JQ, Li ZJB and Zhu ZM: The relationship between the expression of MMP-2 and p53 and tumor invasion and metastasis in colorectal carcinoma. The Practical J Cancer 24: 39-43, 2009.

19. Yin H, Xu L and Yao HW: New opinions of colorectal cancer in 2010. Chin J Practical Surg 30: 764-768, 2010.

20. Hyslop T, Weinberg DS, Schulz S, Barkun A and Waldman SA: Analytic lymph node number establishes staging accuracy by occult tumor burden in colorectal cancer. J Surg Oncol 106: 24-30, 2012.

21. Gao P, Song YX, Wang ZN, Xu YY, Tong LL, Sun JX, Yu M and Xu HM: Is the prediction of prognosis not improved by the seventh edition of TNM classification for colorectal cancer? Analysis of the surveillance, epidemiology, and end results (SEER) database. BMC Cancer 13: 123, 2013.

22. Livak KJ and Schmittgen TD: Analysis of relative gene expression data using real-time quantitative PCR and the 2(-Delta Delta C(T)) Method. Methods 25: 402-408, 2001.

23. Backer JM, Mendola CE, Kovesdi I, Fairhurst JL, O'Hara B, Eddy RL Jr, Shows TB, Mathew S, Murty VV and Chaganti RS: Chromosomal localization and nucleoside diphosphate kinase activity of human metastasis suppressor genes nm23-1 and nm23-2. Oncogene 8: 497-502, 1993.

24. Kim HD, Youn B, Kim TS, Kim SH, Shin HS and Kim J: Regulators affecting the metastasis suppressor activity of Nm23-H1. Mol Cell Biochem 329: 167-173, 2009.

25. Lombardi D, Lacombe ML and Paggi MG: Nm23: Unraveling its biological function in cell differentiation. J Cell Physiol 182: 144-149, 2000.

26. Yang YQ and Li JC: Correlation of genetic instablity of nm $23 \mathrm{H} 1$ and clinicopathologic features of epithelial in ovarian carcinoma. Ai Zheng 25: 713-717, 2006 (In Chinese).

27. Zheng HX, Cui YX, Shen DL, Peng A and He YL: Influence of nm23-H1 gene transfection on expression of MMP-9 and TIMP-1 in lung cancer cells. Chin Clin Oncol 20: 104-107, 2015.

28. Dusonchet L, Corsale S, Migliavacca M, Calò V, Bazan V, Amato A, Cammareri P, Totaro MS, Agnese V, Cascio S, et al: Nm23-H1 expression does not predict clinical survival in colorectal cancer patients. Oncol Rep 10: 1257-1263, 2003.

29. Song JM, Kelton G and Wang JJ: Review colorectal cancer screening: Current available methods. Chin General Practice 11: $1115-1120,2008$.

30. Zhao R, Gong L, Li L, Guo L, Zhu D, Wu Z and Zhou Q: $\mathrm{Nm} 23-\mathrm{H} 1$ is a negative regulator of TGF- $\beta 1$-dependent induction of epithelial-mesenchymal transition. Exp Cell Res 319: 740-749, 2013.

31. Selivanova G: Wild type p53 reaction: From lab bench to clinic. FEBS Lett 588: 2628-2638, 2014.

32. Chang YS, Graves B, Guerlavais V, Tovar C, Packman K, To KH, Olson KA, Kesavan K, Gangurde P, Muknherjee A, et al: Stapled $\alpha$-helical peptide drug development: A potent dual inhibitor of MDM2 and MDMX for p53-dependent canceer therapy. Proc Natl Acad Sci USA 110: E3445-E3454, 2013.

33. Zhou XF, Zhang G and Tian Y: P53 status correlates with the risk of recurrence in non-muscle invasive bladder cancers treated with bacillus calmette Guérin: A meta-analysis. PLoS One 10: e0119476, 2015.

34. Dolicanin Z, Velicković LJ, Djordjević B, Visnjić M, Pesić I, Ristić A and Marianović V: Expression of regulatory proteins and proliferative activity in relation to phenoty pic characteristics of upper urothelial carcinoma. Vojnosanit Pregl 68: 567-574, 2011.

35. da Silva GN, Evangelista AF, Magalhães DA, Macedo C, Búfalo MC, Sakamoto-Hojo ET, Passos GA and Saladori DM: Expression of genes related to apoptosis, cell cycle and signaling pathways are independent of TP53 status in urinary bladder cancer cells. Mol Biol Rep 38: 4159-4170, 2011. 
36. Chen XY, Shi ZL and Li YH: Co-expression of P-gp, GST, TOP II and p53 in colorectal carcinoma. J Clin Exp Pathol 18: 608-610, 2002

37. Lu Y, Gao J and Lu Y: Down-expression pattern of Ku70 and p53 coexisted in colorectal cancer. Med Oncol 32: 98, 2015.

38. Ye B, Wang XC, Lei L and You LS: Expression and clinical significances of p53 and Ki67 in colorectal carcinoma. The Practical J Cancer 28: 42-44, 2013.

39. Liu BW, Liu Y, Liu JR, Feng ZX and Liu T: Prognositic effect of p53 expression in patients with completely resected colorectal cancer. Tumour Biol 35: 9893-9896, 2014.
40. Geng QQ,Li Y, Tang CH,Li EX, Wu YY and Zhang GJ: Expression and clinical significance of vascular endothelial growth factor-C and $\mathrm{nm} 23-\mathrm{H} 1$ in stage II and III colorectal carcinomas. Zhonghua Zhong Liu Za Zhi 35: 439-444, 2013 (In Chinese).

41. Radović S, Dorić M, Hukić A, Babić M, Kuskunović S and Spahović N: Immunohistochemical expression and significance of $\mathrm{Nm} 23$ suppressor protein in primary gastric adenocarcinoma. Bosn J Basic Med Sci 13: 72-77, 2013.

42. Porebska I, Kosacka M, Wyrodek E and Jankowska R: Expression of $\mathrm{p} 53$, bcl-2 and nm 23 protein in squamous cell lung cancer. Pneumonol Alergol Pol 77: 131-137, 2009 (In Polish). 